Euskal ikerketen aldizkaria | Revue d'études basques |

Revista de estudios vascos | Basque studies review

$19 \mid 2016$

Numéro XIX

\title{
Azkaingo erakusleak
}

Maitena Duhalde De Serra

\section{OpenEdition}

\section{Journals}

Édition électronique

URL : https://journals.openedition.org/lapurdum/3339

DOI : 10.4000/lapurdum.3339

ISSN : 1965-0655

Éditeur

IKER

Édition imprimée

Date de publication : 1 janvier 2016

Pagination : 231-237

ISBN : 978-2-95534-134-6

ISSN : $1273-3830$

\section{Référence électronique}

Maitena Duhalde De Serra, «Azkaingo erakusleak», Lapurdum [Linean], 19 | 2016, Sarean emana----an

01 janvier 2021, kontsultatu 03 septembre 2021. URL: http://journals.openedition.org/lapurdum/3339 ; DOI: https://doi.org/10.4000/lapurdum.3339

Creative Commons - Attribution - Pas d'Utilisation Commerciale - Pas de Modification 4.0 International - CC BY-NC-ND 4.0 


\section{Azkaingo erakusleak}

Maitena DUHALDE DE SERRA

UPPA-IKER, UPV/EHU

\section{Sar-hitza ${ }^{1}$}

Lapurdi itsas hegiko euskara edo "kostatar" mintzaira, lapurteraren azpieuskalki bezala ikusi zuen XIX. mendeko Louis Lucien Bonaparte dialektologoak, baita XX. mendean haren sailkapena segitu zuten Julien Vinsonek (1907: 629) eta Pedro de Yrizarrek (1997) ere. J. Vinsonen arabera, hizkera hau zortzi herritan mintzatzen zen: Azkainen, Bidarten, Biriatun, Donibane Lohizunen, Getarian, Hendaian, Urruñan eta Ziburun (1907: 629). Gaur egun, Koldo Zuazo ikerleak nafar-lapurtera euskalkian sartaldeko eta sortaldeko azpieuskalkiak bereizten ditu. "Kostatarra" agerian ematen du, erdialdeko euskararen eta nafar-lapurtarraren arteko lotura egiten du [ela] gehituz (2014: 142). Haren hitzetan, Lapurdi itsas hegiko euskara sei herritan bakarrik mintzatzen da, Getaria eta Bidarte kanpo uzten baititu.

Nahiz eta interes bereziko lanak eginak izan diren, ohartarazi behar da kostatarra guti aztertu dela. Hona zer dioen K. Zuazok oro har ekialdeko hizkerei buruz: Ipar Euskal Herrikoa da denetan ezezagunena, eta galbide lasterrean doazkigu alderdi hartako hizkerak. Edo berdintzen, galtzen ez direnak (2006: 99).

Lapurdi itsas hegiko euskarari buruzko ezagutzaren aberasteko helburuarekin, ikerlan

1. Eskerrak "Lapurdi itsas hegiko euskara" tesi zuzendaritza haien gain hartzen duten Iñaki Caminori eta Xarles Videgaini. Milesker Iñaki Caminori eta Beñat Oyharçabali, lan honentzat ekarri laguntzarentzat eta zuzenketentzat. Eskerrak nire galderei erantzuteko prest izan diren Azkaingo berriemaileei, batez ere Azarete andereari eta Errandonea jaunari. 
labur honetan, kostatarraren parte den Azkaine herriko erakusleei interesatuko gara. Azkaingo berriemaileen ahotik bildu datuak ekarriko ditugu, lekuko horiek dialektologian ohikoak diren irizpide zehatzei esker hautatu ditugularik (Camino 2009: 295-300; Chaurand 1972: 189-190): adinekoak izatea, inkesta egiten den herri horretan beti bizi izana izatea, ahalaz bi burasoak eta ezkontidea herri horretakoak izatea, guti eskolatuak. Datu horiek hizketa librean zein inkesta moduan bildu ditugu. Jasoriko elementuak inguruko hizkerekin konparatzeko, gure esku diren ikerlanak aintzat hartu ditugu.

Azkaingo mintzairaren bilakaera ere kontuan hartzeko nahiarekin, XVIII, XIX eta XX. mendeko tokiko hiru azkaindarren obrak aztertu ditugu: Michel Chourioren Jesu-Christoren Imitacionea (1720), Etienne Lapeyreren Kredo edo sinhesten dut esplikatua (1891), Jean Elissalderen Azkaine gure sorterria (1952-1957).

Fonetika-fonologiaz bi hitz erraiteko, gaur egun, kostatarra osatzen duten bertze hizkeretan bezala, Azkaingo ahozko euskaran hasperena galdua dela zehaztu behar da. Galtze hau berria dela argitu zuen Koldo Mitxelenak (1990 [1961]: 103). Kontuan hartu ditugun hiru idazleek $h$ letra darabilte eta haren erabilera erregularra da. Baina ahozko hizkerari doakionez, XIX. mendeko L.L. Bonaparteren datuak kontuan harturik, Lapurdi itsasaldeko herrietan hasperenik ez dago, Azkainen, Bidarten eta Getarian salbu. XX. mende erdian ere, Roger Gimetek "Le Kostatar" artikuluan galtze horren berri eman zuen Lapurdi itsas hegiko euskaran: la chute de l' "aspiration", fait absolument acquis aujourd'hui, tout au moins dans la prononciation spontanée et naturelle (Gimet 1950: 395).

Gure inkestetan ez dugu hasperen argirik aditu. Hala ere, Azkainen hasperen ahul batzuk entzun ditugu hitz hastapenetan: ${ }^{\mathrm{h}}$ an eta ${ }^{\mathrm{h}}$ ek 'haiek'. Auzo duen Ziburuko herrian ere adibide bakarra bildu dugu: ${ }^{\mathrm{h}}$ ola. Etsenplu urriegi ditugu ondorio argien ateratzeko, baina atzeman ditugun hasperenaren aztarnak erakusleetan eta eratorrietan fosildurik entzun ditugula zehaztu nahi dugu.

\section{Erakusleak}

Erakusleen funtzioa zerbait seinalatzea da eta dakigun bezala, euskarak hiru gradu bereizten ditu (Hualde $\&$ Ortiz de Urbina 2003: 123): proximal '(h)au(r)', mesial '(h)ori' eta distal '(h)ura'.

Hiru maila horiek, hurbilen den objektua, hain hurbil ez dena edo urrun dena seinalatzen dute (Lafitte 1962 [1944]: 83-84). Baita hizketan ari dena, entzuten ari dena eta solasean parte hartzen ez duena ere. Graduazio hori espazioari zein denborari doakie.

Maila horiek balio nozionala izan dezakete. Lehen mailak heldu den informazioa iragartzeko balio izan dezake eta bigarrenak aitzinetik adierazia adierazteko.

Zenbait erran moldetan, lehen eta bigarren mailako erakusleek harridura adierazteko eta hirugarren mailak zentzu enfatikoa izan dezaketela dio Pierre Lafittek. Hona dakartzan adibideak, hurrenez hurren (84): Hau da lana!; Hori, hori gurea!; Axular harek zion bezala.

\subsection{Formak: singularrean}

Hona nola agertzen diren Azkainen erakusle singularrekoen formak, taula batean kasuen arabera sailkaturik: 


\begin{tabular}{|c|c|c|c|}
\hline & Hau & Hori & Hura \\
\hline Absolutiboa & au & ori & ura \\
\hline Ergatiboa & unek & orrek & arrek arreri \\
\hline Datiboa & uni & orri & aren, arren \\
\hline Genitiboa & unen & orren & arekin, arrekin \\
\hline Soziatiboa & unekin & orrekin & artaz \\
\hline Instrumentala & untaz & ortaz & artan \\
\hline Inesiboa & untan & ortan & artarik \\
\hline Ablatiboa & untarik & ortarik & ortarat \\
\hline Adlatiboa & untarat & & \\
\hline
\end{tabular}

Euskara zaharrean, lehen mailako erakusleak, baita 3 eta 4 zenbatzaileek ere, -r- dute bukaeran. Nafarroa Behereko idazkien arabera, XIX. mende arte forma zaharra nagusi dela erakutsi du Iñaki Caminok (2008: 142). Azkaingo euskaran, absolutibo singularreko erakuslea, baita zenbatzaileak ere, bukaera soildurik ahoskatzen dira. Dirudienez, berrikuntza hori gutienez XVIII. mendetik sartua da aztertzen dugun mintzairan. Izan ere, M. Chourioren idazkian forma soilduak ditugu: hau (99), lau (267), baita laugarren (267) ere. Haatik, dardarkaria du hirurgarren ordinalak $(176,181,409)$.

Hark hirugarren mailako erakusleko eta nork izenordain galdetzaile pertsonaleko -rkkontsonante taldea soiltzeko joera izan da Nafarroa Behereko euskaran (Camino 2008: 142). Aztertzen dugun hizkerak bertze bide bat hartu du, hark mailako erakuslea gaur egun harek ahoskatzen baita. M. Chouriok harc erabiltzen du (339), baina E. Lapeyrek (57) eta ondotik J. Elissaldek ere harek (6).

Donibane Lohizuneko euskarari buruzko oharretan, Louis Lucien Bonapartek XIX. mende erdian harek, harrek eta hark formak bildu zituen (BDV m/s Bv. 75²). Azkainen egin ditugun inkestetan, berriemaileei hark arrotza zaie. Genitiboan, aren eta arren forma komunez gain, hizketa librean aken ere bildu dugu. Ebakeraren aldetik, arek eta aRek, aren eta aRen, arekin eta aRekin entzun ditugu. Bi forma horiek bildu ditu Lapurdi barnealdean kokaturiko Larresoroko hizkera aztertu duen Irantzu Epeldek ere (2003: 112).

P. Lafitteren gramatikan adierazi bezala, nafar-lapurtera literarioan, absolutiboan salbu, erakusleen erroak hauek dira singularrean (82): hun-, horr-, har-. Hala da aztertzen dugun hizkeran ere. Hona zenbait adibide idazlanetan: hunequiñ (Chourio 1978: 97), horrec (216), harequiñ (373), huntan (Lapeyre 1982: 58), horri (62), harek (76), hunek (Elissalde 1985: 40), horrekin (39), haren (76).

2. BDV m/s Bv.75: L.L. Bonaparteren euskal eskuizkribuak, 2C2 mikrofilma (Arana, J. A. \& Gonzalez, C. 1989: 42). 


\subsection{Formak: pluralean}

Hona Azkaingo erakusle pluralen formak, kasuen arabera sailkaturik:

\begin{tabular}{|c|c|c|c|}
\hline & Hau & Hori & Hura \\
\hline Absolutiboa & auk, aukiek & oik, oriek, oikiek & eiek, ek, ekiek \\
\hline Ergatiboa & auk, aukiek & oik, oriek, oikiek & eiek, ek, ekiek \\
\hline Datiboa & aueri, aukieri & o(r)ieri, oikieri & eieri, ekieri \\
\hline Genitiboa & auen, aukien & o(r)ien, oikien & eien, ekien \\
\hline Soziatiboa & auekin, aukiekin & o(r)iekin, oikiekin & eiekin, ekiekin \\
\hline Instrumentala & autaz, aukietaz & oitaz, orietaz, oikietaz & eietaz, ekietaz \\
\hline Inesiboa & autan, aukietan & oitan, orietan, oikietan & eietan, ekietan \\
\hline Ablatiboa & autarik, aukietarik & oitarik, orietarik, oikietarik & eietarik, ekietarik \\
\hline Adlatiboa & autarat, aukietarat & oitarat, orietarat, oikietarat & eietarat, ekietarat \\
\hline
\end{tabular}

\subsection{1 auk, oik eta oriek, eiek eta ek}

Lehen graduko pluralaren hiru aldaera ekartzen ditu P. Lafitte gramatikariak, azken bien pluralean, kasu lokatiboek e galtzen dutela gehituz (83). Hona hiruen aldaerak inesiboan: hauietan, hautan, hotan. Hok ageri da Nafarroa Behereko euskaran (Camino 2004: 468). Edu Zelaieta dialektologoaren hitzetan, Baztango Basaburuan adinekoek ok erakuslea darabilte, gazteek berriz, gero eta gehiago okek (2008: 178). Lapurdiko eremura hurbilduz, hau- dugu Larresoroko mintzoan eta epentesiarekin edo gabe ahoskatzen da (Epelde 2003: 112): hau(i) ek, hau(i)eri, hau(i)en. Azkainen epentesi hori ez da agertzen, ez eta (h)ok monoptongaturik ere. Izan ere, (h)au- dugu idatzian eta forma hori gorde da ahozkoan. Hona etsenplu batzuk gure idazleen obretan: hautaz (Chourio 1978: 398), hauk (Lapeyre 1982: 65), hautarik (117), hautako (254), hautan (Elissalde 1985: 108).

Bigarren graduko pluralean, nafar-lapurtera literarioaren gramatikan, Lafittek hoik eta horiek atzematen ahal direla zehazten du (82). Bi forma horiek Nafarroa Behere guzian (Camino 2004: 468), baita Lapurdi barnealdean ere (Epelde 2003: 112) agertzen dira. Gure inkestetan, oriek eta oik bildu ditugu, baina M. Chourio eta E. Lapeyrek lehen aldaera darabilte: horiec abs. (Chourio 1978: 387), horiek erg. (Lapeyre 1982: 67).

Hirugarren graduko pluralari doakionez, ek eta eiek aditu ditugu. (H)ek erakuslea Ipar Euskal Herrian, Nafarroako Pirinioetan eta Baztan-Bidasoan erabiltzen da (Camino 2011: 106). Forma honen bilakaera haiek $>$ heiek $>$ heek $>$ hek dela hipotesia baldin badago ere, Julen Manterolaren ustez, forma zaharra bokal bakarrekoa da (2009: 267). Azkaingo M. Chouriok 
hec abs. (37), hec erg. (98), hetaz (161) hetan (52) hetaric (53), hei (62) formak ditu.

E. Lapeyrek eta J. Elissaldek heiek forma pertsona izenordain bezala erabiltzen dute: Heiek nahiko eta igurikitzen zuten, Errege botheretsu eta gloriaz inguratua izanen zen Mesias edo Salbatzaile bat (Lapeyre 1982: 150-151); Haurrak utzi ditu Baltatzarrek eta heieri bere jakitatea (Elissalde 1982: 89). Hek forma berriz, erakusle zein pertsona izenordain bezala: Erro hek beraz konbertitu ahal izan dute mundua; erro hek herrautsetan eman dituzte Jainko faltsoak (...) (Lapeyre 1982: 213); Beldurtzeko da aspaldi hila dela, Azantza eta Kaskoina bezen pilotari handia zelarik, hek bezalako fama utzi gabe (Elissalde 1985: 112). Gure berriemaileek, eiek erakusle eta pertsona izenordain bezala onartzen dutela segurtatu digute, haatik, hizketa librean ez dugu erakusle bezala bildu.

Larresoroko euskaran (Epelde 2003: 300), baita Beskoitzekoan ere (Camino 2004: 468), pluraleko erakusleak bereizten ahal dira: hauk, hoik, hek absolutiboan nahiz ergatiboan, baina hauek, hoiek, heiek beti ergatiboan.

Berrikuntza hau Nafarroa Beherean arrotza da eta Lapurdi mendebaldera begira, ez dirudi Azkaineraino zabaldu den, egin ditugun inkestetan bederen ez zaigu agertu. Hona J. Elissalderen idazlanetik harturik, lehen mailako hauk erakuslea absolutiboan eta bigarrena berriz ergatiboan: Badakizue guk sasi-mirikuak deitzen ditugun sendagile hauk nola deitzen zituen gure herritar Hiribarrenek? (91); Manuel mundu guzian ezagutua zen jada, pertsu hauk frogatzen duten bezala: (...) (111).

\subsection{2 aukiek, oikiek eta ekiek}

Aktibo pluralean, autore zaharrek haukiek, eta hekiek darabiltzatela zehaztu zuen P. Lafittek (82). Iñaki Caminok, Lapurdi eta Nafarroa Garaiko euskalkiez diharduela, Lapurdin pluraleko erakusle genitiboa absolutiboko aldaeraren gainean eraiki d[ela] zehazten du eta Materraren, nahiz Axularren hauken eta heken adibideak ematen ditu (2013: 128).

Lehen mailako erakusle honen aldaera hiru azkaindarren idazlanetan agertzen da: hauquien (Chourio 1978: 359), haukietan (Lapeyre 1982: 58). haukiekin (Elissalde 1985: 15). E. Lapeyreren idazlanean, bigarren mailean hoiki- ere badugu eta behin hoki-: hokien (120), hoikien (124), hoikieri (76), hoikientzat (74), hoikietan (249). M. Chourio eta J. Elissalderen idazlanetan aldiz, ez dugu aldaera honen berririk. Hirugarrena, M. Chourio eta E. Lapeyrek darabilte, baina J. Elissalderen obran ez da agertzen: hequiequiñ (Chourio 1978: 488), hequiñtzat (161), hequientçat (403), hequien gatic (159), hekien (Lapeyre 1982: 107), hekietarik (82).

Azkainen, gaur egun, auk formaz gain, aukiek baita aukek ere oraindik erabiltzen dituztela ziurtatu digute lekukoek, nahiz eta ez ditugun hizketa librean egin grabaketetan forma horiek bildu. Bigarren mailan, oikiek, baita okiek bezalako formak ere entzun ditugu, baina azken hori gutitan. Hirugarren mailan, genitiboa adibidetzat harturik, ekien bildu dugu eta gutiagotan eiken eta eken. Berriemaile baten hitzetan, Azkainen aiken, aikiekin bezalako formak badaude, baina ez ditugu hizketa librean behin ere aditu.

L.L. Bonaparteren Donibane Lohizuneko euskarari buruzko oharrei begiratuz, Azkainen entzun ditugun erakusle berdinak bildu zituen: lehen mailan haukiyek, haukiyen, haukiyetako; bigarrenean hoikiyek, hoikiyen, hoikiyetako; hirugarrenean hekiyek, hekiyen, hekiyetako (BDV m/s Bv. 75). Azkainerekin mugan den Sarako herrian, hauki- eta heki- aldaeren berri ematen digu, hoiki- berriz, ez da agertzen: haukien, hauki, haukiei; hekien, heki, hekiei.

Lapurdi eremuan den Larresoro herrian aldiz ez dugu haukiek, hoikiek eta hekiek bezalako erakuslerik (Epelde 2003: 112). Bortzerrietan, Malerrekan eta Bertizaranan, okeri 'hauei' eta Baz- 
tanen okei 'hauei', ekei 'haiei' formak ditugu (Zelaieta 2008: 179). Baztangoizan berriz, oki bildu du E. Zelaietak eta haren hitzetan, forma berdinak dira Zugarramurdi-Urdazubin nahiz ondoko Lapurdi eta Behe Nafarroako herrietan (179). Baztango euskalkia ikertu duen P. Salaburuk ere, Elizondoko errekatik goiti aldera joanez entzun daitezkeen erakusleen aldaeren berri ematen digu (1984: 201): hekin eta hekekin; hetaik eta heketaik; hetan eta heketan; hetara eta heketara.

\section{Ondorio gisa}

Erakusleen pluraleko formak aipatu ditugularik, maila bakoitzarentzat, Azkainen forma bat baino gehiago erabiltzen direla ikusi dugu: auk, oik eta oriek, eiek eta ek; aukiek, oikiek eta ekiek. Azken hiru hauek forma berriak dira, baina ez dituzte erakusle zaharrak ordezkatu, gure berriemaileen ahotik denak bildu baititugu, maiztasun berdintsuarekin. Hala ere, lehenago zehaztu bezala, lehen mailako aukiek hizketa librean ez dugu sekulan entzun. Erabilerari doakionez, heiek erakuslea pertsona izenordain bezala erabiltzen dela dirudi, baina ez dugu mota honetako bertze bereizketarik ikusten jakin.

Azkainen bildu ditugun erakusle pluralen aldaera berdinak entzun zituen L.L. Bonapartek Donibane Lohizunen XIX. mendean: hauk eta haukiyek; hoyek, hoik eta hoikiyek; hek eta hekiyek (BDV m/s Bv. 75). Hauki-, hoiki- eta heki- formak kostatarra osatzen duten sei herrietan entzun ditugu. Getarian, mementoan bederen, berriemaile bakarra inkestatu dugu eta hark aldiz, nahiz eta ezagutu, ez ditu erabiltzen.

Bukatzeko, gure eremuaren ekialdeko herrietan datuen biltzeko premia izanen dugula badakigu, baina lan honen osatzeko, L.L. Bonaparteren datuei begiratu diegu. Lehen eta hirugarren mailan, hauki- eta heki- formak jaso zituen Sarako euskaran, baina bigarren mailako hoiki- formaren berririk ez dugu haren eskuizkribuetan. Baztanen erabiltzen diren hekekin, heketaik, bezalako erakusleak, ez dira arrotzak Azkaindarrentzat. Hizketa librean batzuk ere jaso ditugu, nahiz eta ez diren maiz erabiltzen.

Edouard Bourciezek 1895an bildu euskarazko testuak begiratzen baditugu, frantsesezko "quel est donc ce bruit?" itzultzeko, lehen eta bigarren mailako erakusleak erabili dituzte euskaldunek. Lapurdiko eremuari begiratzen badiogu, itsas hegiko herriek hau erakuslea dute (Ziburuk eta Biriatuk salbu), baina Senperetik ekialdera aldiz, hori baliatzeko joera izan dute (Aurrekoetxea, Videgain \& Iglesias 2005: 51). Datu hauek ikusirik, formak eta aldaerak ez ezik, erakusleen hiru mailen erabilera bera ere aztertzeak interes berezia izan dezakeela dirudi.

Lan labur honetan, Azkaingo erakusleei buruzko ohar zenbait ekartzen entseatu gara. Haatik, deskribapen hori zehaztea, kostatarra osatzen duten bertze hizkerekin baita inguruko mintzairekin konparaketa sakontzea ere premiazkoa iruditzen zaigu, Lapurdi itsas hegiko euskararen ezaugarriak argitu nahi baditugu.

\section{Erreferentziak}

Aurrekoetxea, Gotzon; Videgain, Xarles \& Iglesias, Aitor. 2005. "Bourciez" bildumako euskal atlasa (BBEA). 2. Gramatika. ASJU 39. 1-277.

Bonaparte, Louis Lucien. (XIX. mende erdia) Contestaciones a cuestionarios dialectológicos en el País Vasco-Francés. Notas referentes a Ahetze, Aïnhoa, Arbonne, Arcangues, Armendarits, Aroue et Etcharry, Ascain, Ayherre, Bardos, Bassussarry, Bidart, Bonloc, Cambo, Baïgorry, Briscous, Espelette, Guéthary, Hasparren, Hélette, Iholdy, Irissarry, Isturits, Itxassou, Lahon- 
ce, Larressore, Louhossoa, Macaye, Mendionde, Mouguerre, Saint-Esteben, Saint-Jean-deLuz, Saint-Jean-Pied-de-Port (Baissassarry), Saint-Martin (Méharin), Saint-Palais, SaintPée, Saint-Pierre-d'Irube, Sare, Tardets, Urcuit, Urrugne, Ustaritz, Villefranque, argitaratu gabeko 30. eskuizkribua, BDV m/s Bv 75.

Camino, Iñaki. 2004. Nafarroa Behereko euskara. FLV 97. 445-486.

Camino, Iñaki. 2008. Nafarroa Behereko euskara zaharra. ASJU 42. 101-170.

Camino, Iñaki. 2009. Dialektologiatik euskalkietara tradizioan gaindi. Donostia: Elkar.

Camino, Iñaki. 2011. Ekialdeko euskararen iraganaz. ASJUren gehigarriak LXIX. 87-153.

Camino, Iñaki. 2013. Euskalkien historiaz: Lapurdi eta Nafarroa Garaia. In Gómez, R., Gorrochategui, J., Lakarra, J.A. \& Mounole C. (arg.), Koldo Mitxelena Katedraren III. Biltzarra. UPV/EHU, Vitoria-Gasteiz. 77-140.

Chaurand, Jacques. 1972. Introduction à la dialectologie française. Paris-Bruxelles-Montréal: Bordas.

Chourio, Michel. 1978 [1720]. Jesu-Christoren Imitacionea. 1788. urteko edizioaren faksimilea. Donostia: Hordago.

Elissalde, Jean. 1985 [1952-1957]. Azkaine gure sorterria. Donostia: Elkar.

Epelde, Irantzu. 2003. Larresoroko euskara (Dialektologia azterketa). Doktoretza-tesia argitaragabea. Zuzendaria: K. Zuazo, UPV/EHU.

Hualde, José Ignacio \& Ortiz de Urbina, Jon. 2003. A Grammar of Basque. Berlin, New York: Mouton de Gruyter.

Gimet, Roger. 1950. "Le Kostatar." Dialecte basque de la région de St. Jean-de-Luz. Eusko Jakintza 4. 221-250 eta 393-424.

Lafitte, Pierre. 1962 [1944]. Grammaire basque (navarro-labourdin littéraire). Édition revue et corrigée. Bayonne: Amis du Musée Basque et Ikas.

Lapeyre, Etienne. 1982 [1891]. Kredo edo sinhesten dut esplikatua. L. Villasanteren argitalpena. Bilbo: Euskaltzaindia.

Manterola, Julen. 2009. Erakusleak berreraikitzen: arazoaren beste alderdi bat. Lapurdum XIII. 261-275.

Mitxelena, Koldo. 1990 [1961]. Fonética histórica vasca. Donostia: Gipuzkoako Foru Aldundia.

Salaburu, Pello. 1984. Hizkuntz teoria eta Baztango euskalkia: Fonetika eta Fonologia. Bilbo: Euskal Herriko Unibertsitatea.

Vinson, Julien. 1907-1911. Spécimens de variétés dialectales basques. RIEV 1. 627-633. RIEV 2. 129-135. RIEV 5. 211-223.

Yrizar, Pedro. 1997. Morfología del verbo auxiliar labortano (estudio dialectológico). Iruñea: Euskaltzaindia \& Euskal Herriko Unibertsitatea.

Zelaieta, Edu. 2008. Baztan-Bidasoako hizkeren azterketa dialektologikoa. Bilbo: Nafarroako Gobernua eta Euskaltzaindia.

Zuazo, Koldo. 2006. Deba Ibarreko euskara. Dialektologia eta Tokiko batua. Oñati: Badihardugu Euskara Elkartea.

Zuazo, Koldo. 2014. Euskalkiak. Donostia: Elkar. 